\title{
A EXCLUSÃO BANCÁRIA COMO CONSEQUÊNCIA DA MIOPIA DE MARKETING
}

THE BANKING EXCLUSION AS A CONSEQUENCE OF MARKETING MYOPIA

Renato Lúcio Pinho Centro Universitário UNA - MG renato@nicolato.com.br

Fernanda Carla Wasner Vasconcelos Centro Universitário UNA - MG fernanda.wasner@prof.una.br

Cristiana Trindade Ituassu Centro Universitário UNA - MG cristianaituassu@yahoo.com.br

Íris Barbosa Goulart Centro Universitário UNA - MG irisbgoulart@gmail.com

Submissão: $25 / 03 / 2015$

Aprovação: 08/07/2016 


\section{RESUMO}

O objetivo deste estudo foi analisar os desafios da inclusão bancária a partir das dimensões: produtos e serviços; canais de atendimento; comunicação. Os fatores críticos que impactam o sujeito da base da pirâmide social, em especial, o microempreendedor, no acesso e utilização dos produtos e serviços oferecidos pelas instituições bancárias são apresentados ao leitor, com base nos depoimentos de 37 entrevistados, todos micro-empreendedores que mantêm suas atividades no Aglomerado da Serra, em Belo Horizonte - MG. Suas falas foram submetidas a uma análise de conteúdo e os resultados evidenciam, como pontos críticos para uma inclusão bancária eficiente: canais de atendimento alternativos e fisicamente mais próximos; tecnologia segura, de fácil acesso e com uso intuitivo; custo dos produtos e operações financeiras compatível com a população; atendimento de qualidade em todos os canais de atendimento; propaganda específica direcionada para esse público e, por fim, uma política constante de promoção de educação financeira. Segundo os resultados da pesquisa, essas ações poderiam reduzir o distanciamento entre as instituições bancárias e o sujeito objeto do estudo, evidenciando o papel do marketing como potencial instrumento de inclusão.

Palavras-chave: Inclusão bancária; Microempreendedor; Marketing. 


\begin{abstract}
This study aimed at analyzing the challenges of banking inclusion from the dimensions: product and services; service channels; communication. The critical factors that impact the subject at the base of the social pyramid, especially the micro-entrepreneur, when accessing and using financial services and products offered by banking institutions, are presented to the reader based on the statements of 37 interviewees, all of them micro-entrepreneurs who run their businesses in the so-called Aglomerado da Serra, Belo Horizonte - MG. Their responses were submitted to content analysis and the results provide evidence on critical points for effective banking inclusion: alternative and physically closer service channels; user-friendly and easily accessible technology; cost of products and financial operations affordable by the population; good quality customer care in all service channels; specific advertising directed to this target audience and, last but not least, a sustainable policy towards promoting financial education. According to the research results, these actions could shorten the distance between the banking institutions and the subjects under study, which provides evidence on the role played by marketing as a potential inclusion instrument.
\end{abstract}

Keywords: Bank inclusion; Micro-entrepreneur; Marketing. 


\section{INTRODUÇÃO}

Mundo, mercado, redução da pobreza, organizações financeiras, acesso aos serviços e produtos e consumo são termos cada vez mais presentes no cotidiano das pessoas. Dois aspectos principais fundamentam a atenção que esses temas têm recebido. $\mathrm{O}$ primeiro se refere às consequências da exclusão bancária para o agravamento da pobreza, como comenta Yunus (2010). Economista laureado com um Prêmio Nobel, em 2006, Muhammad Yunus defende que a pobreza é um obstáculo à paz. Tido como o criador do microcrédito, confere tanta relevância a serviços financeiros como este que chega a afirmar: ninguém deve ter recusado o acesso a eles, que merecem status de um direito humano, por serem tão vitais para a autorrealização das pessoas, ao lhes proporcionar inclusão e desenvolvimento (YUNUS, 2010). No caso do Brasil, por exemplo, com o êxito da estabilização monetária de 1994, a importância de combater a pobreza tornou-se consenso, a partir da idéia de que ela reflete e sintetiza a face mais crítica dos vários problemas nacionais. Lutar contra a pobreza tornou-se diretriz essencial para diferentes segmentos da sociedade e passou, assim, a envolver diversas iniciativas, dentre as quais aquelas de inclusão bancária para a população de baixa renda (COSTA, 2010).

O segundo aspecto que baseia a relevância desse tema reside na importância da base da pirâmide para a rentabilidade de várias organizações. Nesse sentido, a grande massa populacional que a compõe pode se tornar, muitas vezes, um indicador do tamanho das oportunidades de mercado que representa. É por isso, dentre outros fatores, que países como China, Índia, Indonésia, México, Brasil e outros ainda são citados por autores como Prahalad (2008) como potenciais mercados emergentes. Negligenciar essa parcela da população significaria, para as empresas, perder negócios e a oportunidade de lucros.

Com base nesses dois fatores, os setores público e privado consideraram a necessidade de operar, no âmbito das instituições bancárias, públicas e privadas, com essa parcela da população. Há, portanto, um constante incentivo para que as organizações financeiras se tornem parceiras singulares na promoção do microcrédito, além de outros produtos ou serviços, com o objetivo de ampliar, de forma expressiva, as operações bancárias e, conseqüentemente, a inclusão desses indivíduos no sistema financeiro.

No caso do Brasil, várias são as ações dirigidas à população de baixa renda, conforme relatório publicado pelo Banco Central do Brasil (2011, p.6), como: Programa Nacional de Fortalecimento da Agricultura Familiar - PRONAF (BRASIL, 2014a); Programa Crescer 
(BRASIL, 2014b); Minha Casa Minha Vida; e o Projeto de Inclusão Bancária para Beneficiários do Programa Bolsa Família (PBF) (BRASIL, 2014c). Mas, apesar desses esforços, o resultado desses projetos ainda é incipiente, considerando dados do Ministério do Desenvolvimento Social (MDS, 2011), que apresenta, dentre outros dados, o número de Famílias do Projeto de Inclusão Bancária em relação ao total de famílias envolvidas no PBF: apenas $14,71 \%$ possuíam conta simplificada, em abril de 2011. (BANCO CENTRAL DO BRASIL - BCB, 2011, p. 103).

No Brasil, encontram-se alguns trabalhos sobre consumo dos pobres (CASTILHOS, 2007; MATTOSO, 2013), como também sobre inclusão bancária (ROCHA e SILVA, 2008; RIBEIRO, FURRIER e ACEVEDO, 2010). Entretanto, a abordagem da inclusão bancária a partir da ótica do indivíduo que compõe a base da pirâmide, por meio de informações obtidas em pesquisa de campo, refere-se a um tema ainda novo e pouco investigado.

Diante de constatações como essas, surgiu o interesse de compreender melhor o fenômeno. Para tanto, este estudo se propôs a identificar quais as variáveis que impactam a inclusão bancária do sujeito empreendedor que compõe a base da pirâmide social. Isso foi feito por meio da análise dos desafios da inclusão bancária a partir das dimensões: produtos e serviços; canais de atendimento; comunicação, pensadas para que se identifique a percepção desse sujeito quanto a alguns aspectos que a literatura já apontou como relevantes, nesse contexto (ROCHA e SILVA, 2008; BADER e SAVOIA, 2013).

Este artigo encontra-se estruturado em cinco seções, incluindo esta introdução. A seguinte apresenta a fundamentação teórica da pesquisa, e as demais tratam da metodologia utilizada para desenvolvê-la, da interpretação dos dados e das conclusões do estudo.

\section{FUNDAMENTAÇÃO TEÓRICA}

O referencial teórico deste trabalho foi dividido em dois temas: a base da pirâmide social, exclusão e inclusão bancária.

\section{A base da pirâmide Social}

Muito se discute sobre classes sociais, base da pirâmide ou mesmo estrutura social. Nesse debate, uma importante contribuição para a conceituação das camadas sociais foi a classificação de pobreza proposta por Sachs (2005), ao perceber que não podem, essas 
pessoas, ser incluídas num mesmo grupo e tratadas de forma idêntica. $\mathrm{O}$ autor estabeleceu três grupos de pobreza, sendo: (i) extrema pobreza, constituída pelas camadas com necessidades básicas de alimentação e moradia que não alcançam nenhum atendimento; (ii) pobreza moderada, que inclui as camadas com necessidades básicas sendo atendidas, mas sem, necessariamente, acesso à educação e à saúde, e que, diante de vicissitudes, podem ser levadas à extrema pobreza; (iii) pobreza relativa, que se caracteriza pelas camadas com a renda inferior à média nacional, em que o indivíduo tem acesso aos serviços de educação e saúde de baixa qualidade e sua capacidade de ascender socialmente é limitada.

Castilhos (2007) também nota a falta de homogeneidade dessa parcela da população e descreve a existência de três classes de grau de pobreza, a partir da ótica do sujeito que compõe a base da pirâmide: o pobre-pobre, que não tem onde dormir ou comer, o pobre que tem um pouco mais de condição (tem onde dormir e o que comer) e a elite do morro, constituída pelos bem-sucedidos comerciantes locais. Diante disso, pela limitação de espaço que este artigo impõe, cabe, aqui, apenas lembrar que este estudo focou o subgrupo que envolve microempreendedores, por motivos que serão expostos posteriormente.

É importante, também, chamar a atenção para a idéia de pobreza como uma noção relativa: o pobre é sempre o outro ao qual a pessoa de outra classe se compara (MATTOSO, 2013). Assim, há formas sutis de distinção entre os iguais, como "emprestar o nome" para mostrar que "se está podendo mais que o vizinho" e a adoção de costumes da patroa pelas empregadas domésticas, com a finalidade de se distinguir dentro de seu meio social (MATTOSO, 2013; BARROS, 2006). Como exemplo disso, Sarti (1996), em seu estudo de campo, não encontrou ninguém que se definisse como pobre. Nos bairros da periferia de São Paulo, os pobres eram os que moravam na favela; já na favela, os pobres eram os que moravam embaixo da ponte. Portanto, a pobreza é "uma categoria relativa. Qualquer tentativa de confiná-la a um único eixo de classificação, ou a um único registro, reduz seu significado social e simbólico" (SARTI, 2003, p. 42).

Vários estudos contemplam o comportamento desse público como consumidor. Por exemplo, para Anderson e Markides (2007) citados por Rocha e Silva (2008), os consumidores pobres são sensíveis a quatro fatores: aceitabilidade do produto, preço acessível, sistemas inovadores de distribuição e formas criativas de comunicação. Ribeiro, Furrier e Acevedo (2010), no que se refere à tomada de decisão de consumo por indivíduos de baixa renda, conforme afirmado por Bertrand, Mullainathan e Shafir (2006), citam a existência de fatores de canal, ou facilitadores, como a distância de um ponto de venda, e os 
fatores intervenientes, sobre a resistência ao risco e à cautela de perdas/ganhos. Cunha, Santos e Cerqueira (2013), por sua vez, afirmam que esses consumidores de baixo poder aquisitivo têm mínimo grau de instrução escolar, dificuldade com a pronúncia correta das palavras, além de recursos financeiros limitados. Segundo os autores, o local da compra é aspecto muito importante para esse público. Enquanto isso, Parente e Barki (2005) apontam, como aspecto fundamental para essas pessoas, no momento do consumo, a flexibilidade de crédito, já que, por não participarem do trabalho formal, não tem ganhos regulares.

Assim, diferentes pesquisas abordam aspectos distintos do comportamento de compra dessa parcela da população. Nesse contexto, o presente estudo busca compreender, especificamente, os desafios da inclusão bancária, na percepção do microempreendedor da base da pirâmide social.

\section{Exclusão e inclusão bancária}

Segundo Gloukoviezoff (2006, p. 215), a primeira definição de exclusão financeira apareceu com Leyshon e Thrift (1995, p. 314), para quem a expressão se referiria aos "processos que servem para prevenir que determinados grupos sociais e indivíduos tenham acesso ao sistema financeiro". Essa definição parece restringir o conceito a práticas bancárias excludentes, como localizar agências em áreas com alto nível de renda ou restringir a oferta de produtos devido a custos elevados (CROCCO, SANTOS e FIGUEIREDO, 2013). Por outro lado, o conceito de Gloukoviezoff (2004) se mostra mais amplo. Para o autor, exclusão financeira é o processo em que os indivíduos estão desamparados ou encontram limitações em suas realizações financeiras, de forma que estejam impedidos de desfrutar dos benefícios que estas práticas propiciam na vida diária. Essa visão transcende o debate sobre o acesso e o uso de serviços financeiros, pois envolve também as conseqüências sociais desse fenômeno (CÓRDOVA, DINIZ e GONZALEZ, 2013).

Diferentes autores apontam razões distintas para esse tipo de exclusão, seja por motivos relacionados a ações das empresas desse setor, seja por características desse público, seja por políticas governamentais. Prahalad (2008), por exemplo, afirma que mediadores financeiros formais, como os bancos comerciais, normalmente negligenciam essa parcela da população por causa do alto custo das negociações, a ausência de ativos a receber como garantia, o isolamento geográfico e o preconceito social. Como outros exemplos de fontes de exclusão bancária, citam-se as informações fornecidas sobre os produtos e o design desses 
produtos - relacionados a decisões mercadológicas das instituições financeiras - ou ainda barreiras regulatórias, tecnológicas ou de mercado (HONOHAN, 2005).

Apesar dessas dificuldades que enfrentam, Yunus (2010) lembra que os pobres são pessoas plenamente providas de destrezas e inteligência indispensáveis para se emanciparem da pobreza - desde que tenham a oportunidade de fazê-lo. A partir desse princípio e da vivência numa aldeia de Chittagong, em Bangladesh, ele implantou uma metodologia de microcrédito, criou o Grameen Bank e passou a defender que ninguém deve ser excluído do acesso aos serviços financeiros. A inclusão financeira seria, portanto, matéria de importância global em razão de sua alta virtude social e de seu potencial econômico (BADER e SAVOIA, 2013).

O conceito de inclusão financeira encontra-se associado ao de inclusão econômica; ambos se relacionam aos esforços públicos ou privados que visam promover o acesso dos consumidores ainda não integrados aos serviços econômicos, efetivado por meio do alargamento da disponibilidade de produtos e serviços financeiros, seguros e, também, pela elevação do nível de qualidade da educação dos consumidores com vista à sua conexão aos sistemas bancários. A inclusão bancária se refere à existência de cinco áreas, dentro da inclusão financeira, a serem analisadas: (i) propriedade, ou seja, o indivíduo detém uma conta bancária; (ii) pagamentos, ou a forma como o sujeito paga suas despesas; (iii) crédito, que se refere à forma de empréstimo; (iv) poupança, ou a capacidade do sujeito de poupar e (v) seguros (VERISSIMO, 2012, p. 48). Em meio às estratégias de combate à pobreza, esse acesso ao crédito e a outros serviços financeiros deve ser planejado como um tema primordial, notadamente pelo seu papel no estímulo a atividades econômicas (FREITAS, 2013).

O Brasil registra iniciativas que visam à inclusão bancária já há algum tempo, como o Projeto Democratização do Crédito, desenvolvido a partir de 1990 (SOARES e MELO SOBRINHO, 2008), além de outras ações posteriores, como as mencionadas na introdução deste artigo. Contudo, os resultados parecem incipientes e, como afirmam Ribeiro, Furriei e Acevedo (2010), em países com amplos contingentes populacionais e uma classificação urbana desigual em um território vasto, há dificuldade adicional no tocante à democratização de acesso aos bens e serviços por populações menos privilegiadas. Assim, o tema permanece demandando atenção por parte de governos e empresas, devendo ser visto não só como algo que implica necessárias políticas públicas, mas também como diretriz rentável para as instituições financeiras. 


\section{METODOLOGIA}

A investigação envolveu uma pesquisa de campo de caráter exploratório. Quanto à abordagem, esta foi qualitativa e teve como instrumento de coleta de dados a entrevista semiestruturada, realizada com 37 empreendedores residentes no Aglomerado da Serra - Belo Horizonte, escolhidos pelo critério de acessibilidade, nos meses de julho e agosto de 2014.

A escolha por esse público reflete uma visão segundo a qual o empreendedor é visto não só como aquele que exerce papel fundamental no desenvolvimento econômico (DOLABELA e FILION, 2013), mas também como a força que age em milhares de pequenas e médias empresas, na colaboração e na melhoria social (OLIVEIRA et al., 2014). Além disso, autores como Albagli e Maciel (2002) entendem novos negócios, caracteristicamente dirigidos por proprietários-gerentes ou empreendedores-proprietários, como uma configuração alternativa de inclusão social, de geração de trabalho e renda, no combate ao desemprego e à pobreza em coerência com a perspectiva adotada neste trabalho. Nessa mesma linha, Vale (2014) vê o empreendedorismo não como fenômeno de elite, mas como algo associado às classes médiabaixa e baixa. O autor afirma que é possível perceber o papel relevante dos grupos sociais marginalizados, na tentativa de inserção social: na medida em que não conseguiram se engajar previamente em profissões e carreiras tradicionalmente prestigiadas, muitas pessoas dirigem seus interesses para um espaço possível, cada vez mais difundido: o empreendedorismo. Tudo isso aponta para a relevância do empreendedor no processo de combate à pobreza e remete à discussão sobre inclusão bancária, tema deste artigo. Afinal, essa figura necessita do acesso ao serviço prestado pelas instituições financeiras que, no entanto, muitas vezes lhes é negado. Merece, assim, especial atenção e, por esses motivos, foi escolhida como alvo deste estudo.

Utilizou-se, como técnica de interpretação de dados, a análise de conteúdo de Bardin (2011). Os códigos da análise foram as falas inteiras obtidas, a cada pergunta da entrevista, nos relatos. Utilizou-se, para registrar as respostas desses indivíduos, o gravador (de áudio), com permissão dos sujeitos de pesquisa, como também documentação fotográfica da região investigada. Outro ponto a se destacar foi a observação não participante, usada como técnica complementar de coleta de dados para a obtenção de informações.

\section{Trajetória de pesquisa - amostra e coleta de dados}

Com planejamento prévio, o estudo dessa região ocorreu a partir das informações obtidas ao longo dos trabalhos realizados desde 2011, com microcrédito, no Aglomerado da 
Serra, em Belo Horizonte. Com área de 150 hectares e população de 46 mil habitantes, o Aglomerado é constituído por vilas que começaram a se formar há cerca de 50 anos. Mesmo apresentando uma série de características comuns, estas são diferenciadas entre si, do ponto de vista social, por um conjunto de variáveis, tais como: tempo de ocupação, nível de identidade com o espaço físico-social, nível de organização interna e condições socioeconômicas, variáveis estas determinantes da dinâmica social do Aglomerado (URBEL, 2000). Situado na encosta da Serra do Curral, o Aglomerado é, segundo a Prefeitura Municipal de Belo Horizonte, formado por sete vilas: Marçola (também conhecida como Favela Cabeça de Porco), Nossa Senhora de Fátima, Nossa Senhora Aparecida (conhecida como Favela do Pau-Comeu), Nossa Senhora da Conceição, Santana do Cafezal, Novo São Lucas e Fazendinha. Essas vilas estão inseridas na Regional Centro-Sul da cidade, principal local de residência das parcelas mais ricas da população belo-horizontina e região de concentração máxima de atividades econômicas, especialmente terciárias, além de empregos, equipamentos e serviços públicos. O comércio diversificado, aliado aos serviços disponíveis à população do Aglomerado, tem chamado a atenção de organizações governamentais e não governamentais, em especial, pelas características empreendedoras locais. Diferentemente da região em que se insere e com pouca infraestrutura, o Aglomerado da Serra sofre com a falta de acesso às redes de atendimento aos serviços bancários. Com uma população equivalente a uma cidade de porte médio, a comunidade conta apenas com dois serviços de "Caixa Aqui". Reúne, portanto, características adequadas para se tornar objeto de estudo de uma pesquisa como esta.

A partir da entrevista-piloto que constituiu uma tentativa de coleta de dados sem intermediários ou facilitadores locais, verificou-se a necessidade do uso de um guia, morador do Aglomerado. O facilitador escolhido lá reside e atuou no Projeto BH Negócio, cujo objetivo foi formalizar empreendedores e prepará-los com cursos de gestão, em parceria com a Federação das Associações de Micro Empresas e Empresas de Porte de Minas Gerais (FEMICRO) e o Serviço Brasileiro de Apoio às Micro e Pequenas Empresas (SEBRAE-MG). Esta pessoa, remunerada por cada entrevista realizada, foi parceira da equipe de microcrédito da instituição financeira que desenvolveu o BH Negócio, nos anos de 2012 e 2013.

Posteriormente, estabeleceram-se as principiais características dos entrevistados, considerando as condições do empreendedor do Aglomerado, com base nos relatórios do BH Negócio e no relato dos seus agentes sobre o empreendedor local, sendo também préagendados datas e horários para a realização dessas entrevistas. 
A amostra foi composta por indivíduos empreendedores que possuíam seus negócios no Aglomerado da Serra, em Belo Horizonte, incluindo atividades que envolviam desde lanchonete, açougue, mercearia, salão de beleza, serviços de costura, até venda de móveis, peças íntimas, celulares, roupas, presentes, espetinhos etc. As entrevistas foram aplicadas até que se atingisse a saturação, o que ocorreu após o contato com 37 empreendedores. Elas foram realizadas sempre com a presença do facilitador, que conduziu o pesquisador até o local onde os sujeitos de pesquisa mantêm suas atividades profissionais. Foram entrevistados empreendedores de todas as vilas do Aglomerado da Serra. Posteriormente, os depoimentos foram transcritos pelo próprio pesquisador e categorizados conforme detalhado a seguir.

\section{Quanto à técnica de interpretação dos dados - análise de conteúdo}

Seguindo as etapas prescritas para a análise de conteúdo de Bardin (2011), os dados das entrevistas foram analisados e classificados em categorias, criadas a priori com base na pesquisa de Rocha e Silva (2008), que destacam fatores sensíveis aos consumidores pobres, e no estudo de Bader e Savoia (2013), no que se refere aos fatores críticos para o desenvolvimento de uma nova logística bancária no Brasil.

Ressalta-se que, na transcrição dos trechos das entrevistas, procurou-se conservar o registro linguístico utilizado pelos entrevistados, de modo a reproduzir o mais fielmente possível suas peculiaridades expressivas. Registra-se também que, na identificação das falas, os sujeitos são nomeados como "Entrevistado", independentemente de seu gênero.

$\mathrm{Na}$ fase de classificação das falas nas categorias de análise, foram elaboradas seis planilhas com identificação dos sujeitos da pesquisa e a sequência de perguntas e respostas. A primeira planilha referia-se à caracterização do entrevistado; a segunda descreveu o conteúdo das entrevistas na íntegra, organizado por colunas representando as perguntas, e pelas linhas, identificando os entrevistados; a terceira planilha continha a compilação das categorias que subsidiavam a resposta da pergunta problema. A resultante desta planilha foi a síntese do que traziam os relatos a respeito de: i) produtos e serviços, ii) canal de atendimento, iii) comunicação; a partir do estabelecimento de frequência para cada categoria, surgiu a quarta planilha, que ilustrava essa coletânea na análise dos resultados em todas as suas dimensões; a quinta planilha revelava, por sua vez, os entrevistados participantes da pesquisa, numa síntese elaborada dos dados da primeira planilha, com o objetivo de compor com maior assertividade a análise deste resultado. Por fim, a última planilha se referiu à reunião de críticas distribuídas aos bancos, aos produtos, ao atendimento, ao preço e à propaganda. 
Essa estratégia de utilizar o Excel $^{\circledR}$, separando as informações obtidas nas entrevistas por planilha, foi um fator de sucesso, agilidade, precisão e confiabilidade na análise de conteúdo para a elaboração do resultado final.

\section{APRESENTAÇÃO E ANÁLISE DOS RESULTADOS DA PESQUISA}

Este tópico está dividido em seções que remetem às categorias que impedem ou favorecem o uso e o acesso aos serviços e produtos bancários. São elas: Produtos e Serviços (com as subcategorias: grau de conhecimento, critérios de avaliação de concessão de empréstimo e financiamento, preço e tarifa), Canal de Atendimento (com as subcategorias: proximidade, qualidade do atendimento, serviço call center 0800, mobile banking, caixa eletrônico e acesso a serviços), e Comunicação.

\section{Categoria: Produtos e Serviços}

\section{Percepção do sujeito em relação aos produtos e serviços bancários}

Os resultados obtidos para a categoria "Percepção do sujeito em relação a produtos e serviços bancários" buscaram compreender as dimensões: grau de conhecimento do sujeito em relação aos produtos e serviços ofertados por instituições bancárias e critério de avaliação para contratação de empréstimos ou financiamentos, considerando o que seria mais importante para a avaliação do indivíduo: juros, prazo ou facilidade. Por fim, buscou-se conhecer sua percepção em relação ao custo das operações e tarifas cobradas pelos bancos.

O sujeito desta pesquisa, em sua maioria, percebe o banco como uma instituição útil apenas para o pagamento de contas, pequenos depósitos e também para viabilizar alguns empréstimos. Mesmo considerando a permanente presença desse público no ambiente bancário, como em: canais parceiros (por exemplo, Correspondente lotérico e Caixa Aqui, agências bancárias, internet banking, mobile banking, bancos 24 horas), ele não é acolhido, o que impossibilita a efetividade de sua inclusão por meio do acesso a serviços e produtos disponíveis pelas instituições bancárias. Cordova, Diniz e Gonzalez (2014) afirmam que o desenvolvimento de uma nação tem um grande desafio a enfrentar quanto à construção de um sistema inclusivo, associado a um sistema financeiro saudável e funcional, o que significa avaliar seu acesso e uso pelas pessoas, ressaltando que a exclusão financeira permanece considerável no Brasil. Conforme Relatório do Banco Central do Brasil (2011), é possível 
identificar uma evolução da inclusão financeira (passando de 9\% em 2005 para 21,7\%, em 2010), mas ainda insuficiente e deficiente. Confirma-se essa exclusão por meio do depoimento concedido pelo Entrevistado 1 "o que sei é que recebe conta de água, luz agora tem uns bancos que não estão recebendo, mas só de cliente, dificultando as coisas, tipo assim, tirando você de banco colocando você na loteria."

\section{Grau de conhecimento}

Bader e Savoia (2013) ressaltam a importância da educação financeira no processo de inclusão bancária, assim como a necessidade de ensinar aos entrantes da bancarização ${ }^{i}$ como usar os produtos e serviços bancários. Confirma-se o baixo conhecimento da população pesquisada a respeito dos produtos e serviços dessas instituições.

O objetivo da pergunta "Você sabe me dizer quais produtos ou serviços são vendidos em um banco? Qual você tem necessidade de adquirir?", presente no roteiro da entrevista, foi identificar o conhecimento do pesquisado a respeito de quais produtos e serviços são comercializados ou ofertados pelos bancos. O Entrevistado 29 identificou o financiamento e o empréstimo como sendo os produtos mais significativos das instituições financeiras, conforme o relato: "produto que o banco te oferece no caso é, que vem ao meu entendimento, é empréstimo né, é o produto principal que o banco tem pra vender, no caso empréstimo, financiamento." Outros depoimentos confirmam a impressão de que a maioria dos entrevistados desconhece o universo de produtos e serviços que esse tipo de instituição poderia lhes oferecer, como mostram as falas a seguir:

"Ainda não... tem que descobrir, né..." (Entrevistado 11)

"Olha, assim, é, é, é que, às vezes, pra depositar um dinheiro, né, algum lugar, ou pra pagar uma conta, conta de luz, conta de energia, conta de água, cartão, né, tirar um dinheiro, sacar um dinheiro se tiver, né (risos)..." (Entrevistado 5)

\section{Critério de avaliação de concessão de empréstimo e financiamento}

Este tópico demonstra a percepção do sujeito da pesquisa em relação aos produtos, empréstimo e financiamento, isto é, no momento em que precisa de recurso, qual fator é considerado para financiar sua atividade produtiva e o que irá influenciar a sua escolha ao contratar o produto: juros, prazo ou facilidade.

Nesse contexto, retoma-se Ohanyan (2003), para quem o progresso do setor de microfinanciamento nos países em desenvolvimento é mais que desejável, pois constitui uma 
fonte de crescimento sustentável do ponto de vista econômico, sendo uma ocupação a ser dividida entre entes privados e públicos. Assim, inclusão bancária, microfinanças e microcrédito são vertentes de uma direção que busca trazer à população mais pobre instrumentos de manejo de poupança, crédito, seguro e outros serviços financeiros. No relato do Entrevistado 5, observa-se a importância de um produto que atenda à demanda desse público (no caso desse microempreendedor, o microcrédito atende):

"Hoje, o meu ponto de vista hoje, mas é o juros, né, mas é o juros, porque o juros do banco mesmo... esse negócio mesmo. Como chama o financiamento? Microcrédito com o juros é mais acessível então isso aí ajudou muito, muito, e também o parcelamento é bem, eu tomei foi 20 vezes o total que eu paguei foi 20 vezes. Mas agora o juros normal assim que o pessoal, eu nunca tomei não." (Entrevistado 5)

Segundo Anderloni et al. (2006), um dos fatores de exclusão financeira é a eliminação por preço, quando o impedimento de determinados grupos de indivíduos terem acesso a serviços é motivado pelo valor de comissão, pela tarifa e pelos juros cobrados. Como demonstrado no depoimento anterior, o público-alvo desta pesquisa tem consciência de que o fator crítico para o sucesso de seus negócios está intrinsecamente relacionado às taxas de juros cobrados. Essencial registrar, nesta pesquisa, que o microempreendedor do Aglomerado da Serra tem um nível de esclarecimento significativo quanto à importância de pesquisar as melhores taxas de juros e tarifas, apesar da baixa escolaridade e do pouco conhecimento sobre produtos e serviços bancários, como relatados, também, pelo Entrevistado 35:

"Taxa de juros... os juros... porque hoje tem locais que tá com juros bem abusivos, né. Não puxando o saco pra Caixa, mas em vista assim. Eu nunca peguei empréstimo não... Mas já dei algumas olhadas e os juros mais baixos são da Caixa mesmo... Até agora esse programa que eles estão fazendo agora de empréstimo empreendedor... uma coisa assim, né... microcrédito... as taxas são bem mais baixas..." (Entrevistado 35)

\section{Preço e tarifa}

Anderson e Markides (2007) afirmam que os consumidores pobres são sensíveis a quatro fatores: aceitabilidade do produto, preço acessível, sistemas inovadores de distribuição e formas criativas de comunicação. Neste tópico, analisa-se a percepção do sujeito da pesquisa em relação aos preços e tarifas praticados pelos bancos. 
O público alvo deste estudo confirma a afirmativa de que é sensível a preços cobrados por serviços e produtos dessas instituições. Destaca-se, nos depoimentos dos Entrevistados 10 e 33, essa percepção do microempreendedor pesquisado quanto às tarifas bancárias.

“Ó, mas é o juros, eu tenho medo, eu tenho muito medo do juros, eu já pensei várias vezes, sabe, de pegar o dinheiro emprestado, mas eu fui parar e pensar, é melhor eu esperar, porque às vezes eu vou pagar duas casas em uma só, entendeu, aí eu prefiro esperar, na hora certa de Deus." (Entrevistado 10)

"Poderia ser menor, porque... Como é uma empresa pequena, igual eu te falei, não é uma empresa de grande porte... Igualzim... Eu pago 4,5 na máquina de juros... Fora o do banco... Então, em soma total, tá saindo aí em 7 e 8\% ... Que eu não posso repassar pro meu cliente, então o que quer dizer que, pra mim, que tem um preço, principalmente aqui no Aglomerado, que eu não posso colocar... Vamos supor... Uma escova de 25 reais pra passar no crédito, 10\% já fica praticamente com o banco." (Entrevistado 33)

Essa micro-empreendedora evidencia sua capacidade de focar em resultados ao estratificar seus custos e preços a serem repassados aos clientes. A partir de uma análise financeira numa equação simples e correta, é possível compreender o que Bader e Savoia (2013) afirmam a respeito da necessidade de produtos e serviços serem customizados para atender o público que compõe a base da pirâmide.

\section{Categoria: Canal de atendimento}

\section{Percepção do sujeito em relação a canal de atendimento}

Os resultados obtidos para a categoria "Percepção do sujeito em relação aos canais de atendimento" envolveram as dimensões: proximidade, isto é, se os canais de atendimento estariam próximos ou afastados do sujeito; a qualidade do atendimento prestado; a relação do entrevistado com o call center; se o sujeito da pesquisa utilizaria novas tecnologias para acessar e movimentar sua conta bancária, como o mobile banking. Em relação ao caixa eletrônico, avaliou-se também a facilidade desse microempreendedor na utilização da tecnologia. Além disso, foi observado se esse público tem facilidade de acesso, de forma geral, para consumir serviços e produtos bancários. 


\section{Proximidade}

Bader e Savoia (2013) afirmam que a inclusão financeira ocorre de maneira sinérgica, que combina canais físicos e virtuais, numa perspectiva de viabilidade econômica e financeira, satisfazendo o requisito de possibilidade de uso por parte do consumidor final. Nessa ótica, verifica-se o distanciamento que ainda ocorre entre as instituições bancárias e o sujeito da pesquisa.

Um fator relevante que impacta na inclusão bancária e, consequentemente, propicia esta exclusão é o distanciamento das agências bancárias do Aglomerado. O Entrevistado 5 confirma, em seu relato, a importância desse fator: "o banco mais próximo é a Caixa, lá na

Contorno ${ }^{i i}$. Lá é um pouco meio longe. Ali é muito assim meio cheio de gente, né, então muito assim um pouco difícil pra gente ir lá, né, mas por necessidade a gente é obrigado a ir lá mesmo."

O depoimento a seguir revela o sentimento de exclusão por acesso geográfico conforme descrito por Crocco, Santos e Figueiredo (2013), que afirmam que uma das causas da exclusão financeira relaciona-se à existência ou não de agências e/ou postos de atendimento em uma determinada região. Ressalta-se que, na data da entrevista, o parceiro da Caixa no local estava com suas atividades paralisadas, mas atualmente voltou a seu funcionamento normal. Também se percebe, neste relato, o grau de importância conferida à instituição bancária federal, no caso, a Caixa Econômica, lamentando que nem com esta se podia contar na região, conforme cita o Entrevistado 20:

"O banco da região mais próximo daqui é a Caixa, me facilita porque tem banco lá perto da rua do Ouro ${ }^{i i i}$, a gente desce, posso sacar meu dinheiro, alguma coisa. Só que facilidade aqui perto do Aglomerado, banco não tem nenhum não, aqui nem Caixa Econômica tem, nem Caixa Econômica, a população não tem acesso à Caixa Econômica, ou ela desce lá na Mem de Sá ou na Capivari, então aqui dentro do Aglomerado não tem, tinha um Caixa Aqui, saiu, então banco aqui, praticamente aqui, não tem nenhum, facilidade nenhuma aqui dentro." (Entrevistado 20)

\section{Qualidade no atendimento}

O relacionamento é importante na dinâmica entre banco e clientes. Ao adquirir as informações sobre seu público em tempo real a cada novo intercâmbio, independentemente do meio de relacionamento que empregar (internet, autoatendimento, agência, mobille banking, call center), ter-se-ão recursos de efetividade na consolidação do aprendizado sobre suas demandas e costumes de utilização (BADER e SAVOIA, 2013). A partir desse aprendizado, a 
organização pode se preparar para atender melhor as necessidades do cliente, como apregoa qualquer manual básico de Marketing. Nesse sentido, um fator que favorece a inclusão bancária envolve, portanto, a qualidade no atendimento à população objeto desta pesquisa.

Os depoimentos obtidos traduzem a percepção dos sujeitos entrevistados quanto ao atendimento dos bancos, considerado como de pouco caso e caracterizado pelo desinteresse, envolvendo mau tratamento, funcionários estressados, atendimento rude e demorado. $\mathrm{Na}$ visão da maioria deles, é possível perceber que ainda falta muito para que se sintam acolhidos e respeitados pelas instituições bancárias, como relevam as falas a seguir.

“Já... mau atendimento... trata com indiferença, né, igual assim, eu fico vendo a diferença do microempreendedor pra uma microempresa, pra uma empresa maior... A gente vê que não tem um crédito... A gente se sente, até mesmo... um rejeitado, né, vamos dizer assim." (Entrevistado 27)

O depoimento do Entrevistado 20 evidencia sentimentos de segregação e exclusão, que favorecem a impressão de estar à margem dos serviços e produtos ofertados pelos bancos. Ele foi dado pelo entrevistado, quando questionado se já havia sido abordado por algum funcionário, dentro de agência bancária, com o objetivo de oferta de produto e serviço:

“Não, não... É que a classe média pobre eles não têm aquela questão assim de querer dar informação, de querer dar não... Agora, se eu fosse uma classe média mais alta assim, com certeza eles ia me abordar, mas como sou de classe média baixa, não é tão lucro pra eles querer dar informação, querer colocar a população carente no título de capitalização, no título disso daquilo, não compensa, não é válido, vamos pegar quem tem dinheiro, pra poder investir, porque pobre investir pra quê, não tem dinheiro." (Entrevistado 20)

Esses depoimentos indicam que os bancos agem de forma contrária à ideal, considerando que, segundo estudos desenvolvidos pela Fundação Getúlio Vargas - FGV (2011), os consumidores de baixa renda buscam adquirir produtos que façam com que se sintam incluídos na sociedade e que despertem sensações de pertencimento. Por isso, valorizam o relacionamento face a face e atitudes que demonstrem respeito. $\mathrm{O}$ sentimento relevado pelas falas demonstra, assim, que muito ainda precisa ser feito nesse sentido.

\section{Serviço call center $-\mathbf{0 8 0 0}$}

Um importante canal de atendimento bancário é realizado por call center. A pesquisa revela que o investimento dos bancos quanto aos serviços 0800 tem uma variável de falta de 
segurança percebida por uma parcela do público pesquisado. Nota-se também, em algumas das falas, certa indignação pelos preços cobrados, conforme diz o Entrevistado 20:

"Eles oferecem... 0800... Mas tem a taxa, né, a taxa de adesão, a taxa pra sair, então isso é pega trouxa, pega otário. Você nunca deve, né, deve aceitar: Você acabou de entrar numa promoção gratuita, vai que é um trote, vai que é alguém da cadeia lá. Banco não oferece nada de graça pra ninguém não, nem água, nem café, não só o banco, mas nenhuma instituição física oferece nada de graça pra ninguém, não existe essa instituição que dá cafezinho ou que vai ligar e vai te oferecer promoção gratuitamente não, não existe." (Entrevistado 20)

\section{Mobile banking}

Quanto ao mobile banking, observa-se o receio do sujeito da pesquisa em relação à utilização de novas tecnologias. Esse receio é expresso pela palavra medo e pelo sentimento de insegurança, presente em diversos depoimentos. Assim, mesmo com todo o investimento realizado nesse canal de relacionamento como facilitador de acesso fácil e rápido, o cliente não o percebe como uma ferramenta segura, o que evidentemente dificulta a aproximação entre esse tipo de cliente e as instituições bancárias.

Nesta pesquisa, a maioria dos respondentes relata que não utiliza o mobile banking por não confiar no processo, como afirma o Entrevistado 2: "não, ainda não, essa tecnologia não me pertence não. Até há pouco tempo não usava nem a internet para fazer uma transação bancária. Eu tinha medo, né. Já vi casos que teve pessoas que utilizou inclusive em lan house, que deu problema, então eu não usava não."

\section{Caixa eletrônico}

O caixa eletrônico é um recurso bastante utilizado, até mesmo, pela imposição já constituída pelo racionamento de custo das instituições financeiras, porém fica claro, nos depoimentos, que seu emprego ainda é bastante difícil para a maioria dos entrevistados, haja vista a complexidade do uso da tecnologia para eles, conforme revelado pelo Entrevistado 5:

"Ó, como sou meio analfabeto, se for para só pra sacar dinheiro, não é não, a gente tem a senha anotadinha, aí não é muito difícil não, se for assim. Já pra depositar, aí tem dificuldade, depositar ou pegar cheque, você entende, aí não mexo não." (Entrevistado 5)

Também foram observadas situações em que os respondentes da pesquisa necessitavam de ajuda de terceiros, principalmente, de familiares mais jovens, para superar obstáculos 
encontrados na utilização de uma tecnologia que não favorece os menos esclarecidos e mais velhos, como revela o Entrevistado 6:

"Eu, geralmente, quando vou, vou com minha filha, esses jovens de hoje sabem tudo... Às vezes a gente, como não utiliza muito, não acessa muito computador, essas coisas, às vezes a gente, os nossos filhos vai bem mais rápido, né." (Entrevistado 6)

\section{Acesso a serviços}

Essa categoria contempla um fator que aparece como outro empecilho, além do preço, dificultando o acesso do micro-empreendedor aos produtos e serviços bancários. Ele se refere à burocratização na concessão de crédito, evidenciando que não é só o valor desses produtos e serviços que pode impossibilitar seu consumo, conforme afirmam alguns autores, a exemplo de Rocha e Silva (2008) e Honohan (2005), ao elencarem outros aspectos determinantes da exclusão financeira. Pela fala a seguir, nota-se que esse problema é um dos fatores que os bancos precisam, ainda, considerar a fim de melhorarem sua relação com esse público:

"Ultimamente eu tô querendo fazer um empréstimo maior, né, mas na Caixa, porém eu tô tendo um pouco de difiliculidade, né, porque é muita coisa, é muita papelada que eles pede, sabe! Eles pede muito papel, a gente leva... eles falaram pra mim que esse ano vai liberar pra mim... Eu quero fazer investimento, eu tô pensando em abrir mais uma loja aqui nessa rua, né... Eu só tô esperando o moço decidir, terminar lá... Eu fiz microcrédito, tinha que ser seis, né, mais cinco, né... Menos não faz não, seis pessoas, a gente fez, né... Foi bom... Ajudou bastante, né, subir na vida um pouquinho." (Entrevistado 30)

\section{Categoria: Comunicação}

\section{Percepção do sujeito em relação à comunicação}

Uma das causas de exclusão financeira citada por Anderloni et al. (2006) refere-se à exclusão por marketing, isto é, uma situação em que alguns segmentos do mercado são excluídos pela forma como vendas e publicidades são direcionadas. Bader e Savoia (2013) destacam, igualmente, a relevância da utilização do marketing apropriado ao público, considerando seus interesses e sua localização.

A partir das citações desses autores e das entrevistas realizadas, é possível perceber o distanciamento entre a propaganda e os microempreendedores pesquisados. A maioria dos entrevistados traduz uma indiferença em relação à propaganda, declarando não se lembrar do conteúdo das peças publicitárias, nem do produto divulgado, afirmando que esta comunicação 
não o conduziu a consumi-lo. A declaração do Entrevistado 18, apesar de simples, é direta e retrata essa indiferença em relação à propaganda, "Passa várias propaganda aí, mas não presto atenção não." Outras ainda reforçam essa impressão de apatia:

"Eu sei que teve sim... Bradesco e tal, mas não me recordo não... Itaú teve vários, mas não me recordo não." (Entrevistado 8)

Uma fala impactante em relação à percepção do empreendedor quanto à propaganda veio do Entrevistado 29, quando utiliza uma parte do slogan da propaganda para demonstrar a sua revolta em relação ao serviço prestado.

"Me lembro sim... Me lembro da propaganda do Itaú que falava que o banco era feito pra mim... (risos) Não tem nada feito pra mim lá... Feito pra mim ferrar... Me levou no banco, eu quebrei a cara e tou quebrando até hoje... Verdade." (Entrevistado 29)

Apesar disso, há alguns depoimentos que mostram reflexos positivos do uso dessa ferramenta de comunicação, sinalizando seu potencial para aproximar instituição bancária e cliente - desde que corresponda a suas características, hábitos, expectativas etc. O Entrevistado 10, por exemplo, reforça a importância da propaganda quando afirma que foi, por diversas vezes, buscar informações sobre o programa Minha Casa Minha Vida, graças à divulgação que dele foi feita por meio da propaganda:

"Eu lembro da Minha Casa Minha Vida, nossa, eu fico babando com esse negócio da minha casa minha vida, fui e não fui uma vez só não, fui umas três vez, mas eu não consegui... ééé... Teve informação, ela falou que tem que ter salário, né, e meu salário não dava, só do meu esposo só." (Entrevistado 10).

Falas como essa indicam que há espaço para que a comunicação das instituições financeiras seja mais adequada às particularidades desse público, tornando mais efetivas ações de divulgação dos produtos e serviços dos bancos e facilitando, com isso, a inclusão bancária.

\section{Síntese dos principais resultados}

O Quadro 1 apresenta a síntese dos principais resultados obtidos por meio das entrevistas, divididos por categorias.

Quadro 1 - Síntese dos resultados da pesquisa - categorias, subcategorias e resultado 


\begin{tabular}{|l|}
\hline PRODUTOS E SERVIÇOS BANCÁRIOS \\
Grau de conhecimento - baixo \\
Critério de avaliação de empréstimo e financiamento - juros \\
Valor de tarifa - alto - altíssimo \\
CANAL DE ATENDIMENTO \\
Proximidade - longe \\
Qualidade - ruim e péssima \\
Call center, 0800 - Não confiável \\
Mobile Bank - Não confiável \\
Caixa Eletrônico - Não confiável \\
Acesso a serviços e produtos bancários - baixos \\
\hline COMUNICAÇÃO \\
Importância - indiferente
\end{tabular}

Fonte: Elaborado pelos autores.

Como se pode ver, com relação aos produtos e serviços bancários, os entrevistados apresentaram baixo grau de conhecimento; o principal critério de avaliação de empréstimos e financiamentos são os juros; preços e tarifas bancárias são vistos como altos e altíssimos. As críticas quanto aos canais de atendimento envolvem o fato de estes serem fisicamente distantes, de má qualidade, não confiáveis, de uso complexo e acesso limitado. No que se refere à comunicação dos bancos, os entrevistados se mostraram indiferentes.

\section{CONSIDERAÇÕES FINAIS}

Esta pesquisa teve como objetivo identificar e analisar as variáveis que impactam a inclusão bancária do sujeito microempreendedor que compõe a base da pirâmide social e reside no Aglomerado da Serra, no município de Belo Horizonte, em Minas Gerais.

Percebeu-se, a partir das análises, um distanciamento entre o público-alvo entrevistado e as instituições bancárias, mesmo o microempreendedor reconhecendo a sua utilidade e importância para seus negócios. Observou-se um baixo nível de conhecimento sobre os produtos e serviços comercializados pelas instituições bancárias, sendo elas lembradas apenas para pagamento de conta, pequenos empréstimos e para guardar o dinheiro. Portanto, foram excluídos, dos produtos conhecidos, serviços como: seguros, previdências, fundos, linhas de financiamento ou empréstimos específicos para as necessidades do empreendedor.

No que se refere ao empréstimo, ficou clara a preocupação do público entrevistado com os juros, em relação à facilidade e ao prazo. Esse resultado difere daquele do senso comum, segundo o qual as pessoas que compõem a base da pirâmide social não se preocupam com os juros cobrados e, sim, se a parcela a ser paga se encaixa no seu orçamento. Ressalta-se, 
portanto, o fato de que o sujeito da pesquisa apresenta comportamento distinto por ser empreendedor.

Alinhada a essa informação sobre a preocupação com os juros, está a percepção da existência de cobranças altas, tendo em vista o valor das tarifas praticadas. Os casos mais lembrados referem-se aos extratos extras, mensagem de celular e utilização de máquina de cartão de crédito. Portanto, um fator evidente de exclusão bancária está relacionado ao custo de manutenção da conta, da utilização de máquina de cartão ou à percepção dos juros abusivos dos empréstimos ou financiamento, gerando uma equação custo versus benefício desfavorável para o microempreendedor alvo da pesquisa.

Identificou-se também a percepção dos entrevistados em relação aos diversos canais de atendimento. Algumas reflexões, realizadas a partir dos relatos dos entrevistados, confirmam a importância dos canais parceiros para o sujeito objeto da pesquisa, apesar das críticas em relação às suas limitações, como o valor para recebimento de boleto e a inoperância do sistema. Os depoimentos quanto ao distanciamento das agências bancárias do Aglomerado foram uma realidade presente nas entrevistas, confirmando os estudos de Beck e Torre (2006) que tratam da exclusão bancária devido à limitação geográfica.

Novas tecnologias de atendimento também foram abordadas nesta pesquisa, como o mobile banking. Os resultados evidenciam que esse empreendedor tem sérias restrições para utilizar essa tecnologia, por considerá-la pouco ou nada segura para efetuar a transação bancária. Aparentemente, as instituições bancárias têm realizado grandes investimentos na divulgação do mobile banking. Entretanto, a percepção do sujeito da pesquisa é de que os bancos não se preocupam com a questão de segurança, fator-chave para o acesso dessa população a esse tipo de tecnologia. Situação semelhante foi observada para o 0800 ou call center, ferramenta também vista como pouco confiável.

Outro importante instrumento utilizado para o atendimento da população abordada no estudo é o caixa eletrônico. Ficou evidente, nos relatos, que sua utilização é complexa, pela falta de uma padronização entre os bancos, que usam sistemas distintos (alguns letras, outros digitais). Além disso, a resistência em usar o caixa eletrônico é agravada pelo receio de cometer erros que possam levar a prejuízos financeiros, apesar de os entrevistados reconhecerem que o caixa eletrônico oferece maior comodidade, por ser mais rápido, evitando as filas no interior das agências.

A importância da tecnologia é confirmada por Bader e Savoia (2013), para quem um fator crítico de sucesso das novas tecnologias é sua fácil utilização, que deve ser intuitiva para 
os clientes, sem suscitar resistência, alinhada à percepção de segurança. Diante dos relatos dos entrevistados, pode-se concluir que um importante fator que impede a inclusão bancária efetiva do sujeito objeto da pesquisa, o microempreendedor do Aglomerado da Serra, é a complexidade do uso da tecnologia, aliada à percepção desse sujeito de que ela não é segura.

Outro fator de destaque percebido durante a realização das entrevistas está relacionado ao acesso aos produtos e serviços ofertados pelas instituições bancárias. Além da questão da distância física, a burocracia na concessão do crédito se mostrou um importante obstáculo a ser superado, nesse sentido.

Quanto à qualidade no atendimento conferido a esse cliente, esta é percebida de maneira muito desfavorável. A abordagem dos funcionários, segundo os relatos, é grosseira ou então o banco lhes trata com indiferença. Foi praticamente unânime a informação de que esse sujeito transita no interior das instituições bancárias, em especial, para pagar contas, fazer depósitos e saques, mas não é abordado por funcionários, com o objetivo de ofertar produtos e serviços disponíveis e de orientar tal cliente sobre eles. Daí se pode concluir que é geral o sentimento de sua condição "invisível” dentro das agências bancárias.

Bader e Savoia (2013) reforçam a necessidade de as instituições bancárias desenvolverem um marketing diferenciado que atinja esse público que ainda não é usuário de seus serviços ou produtos. A partir dessa constatação, é possível perceber a importância das respostas obtidas pelas entrevistas, ao considerar a maioria dos respondentes como alheia às ações de marketing promovidas pelo banco.

Nota-se, assim, o afastamento entre o microempreendedor e as instituições bancárias, o que foi confirmado nas entrevistas descritas ao longo deste trabalho. Fatores como distanciamento das agências dos aglomerados, dificuldade de acesso à tecnologia ou percepção de que esta não é segura; marketing não apropriado para o público; produtos e serviços que não atendem às necessidades do sujeito; percepção de que a equação custo versus benefício é desfavorável, o que gera desvantagens para o cliente e reforça o distanciamento do banco ocasionam o efeito exclusão bancária.

Nesse sentido, as conclusões deste estudo apontam para a importância do papel do marketing no desenvolvimento de ações que alterem esse panorama com o qual a pesquisa se deparou. Dentre essas ações, incluem-se: a revisão do portfólio de produtos e serviços dos bancos, de modo a adequá-los às expectativas e necessidades dessas pessoas; uma precificação mais adequada, que leve em conta as limitações desses sujeitos; a aproximação física das instituições bancárias, ainda que por meio de correspondentes; programas de 
treinamento, para capacitar funcionários a lidar com esse público; iniciativas educativas de comunicação, que ensinem essa população a acessar e utilizar serviços financeiros, além dos benefícios de fazê-lo; ações promocionais, que mostrem os investimentos em tecnologia e segurança realizados pelos bancos, para que essas pessoas adquiram mais confiança ao utilizar serviços como o call center e o mobile banking; desburocratização do acesso ao crédito; comunicação dirigida. Imagina-se, contudo, que esse conjunto de ações pouco adiantará se elas não se fundamentarem em decisões estratégicas de segmentação e posicionamento, que deixem de lado essa espécie de miopia de marketing e reconheçam a importância desse público, tanto em termos sociais como fonte de bons negócios.

Acredita-se que iniciativas mercadológicas mais apropriadas do que aquelas que vêm sendo, atualmente, desenvolvidas podem contribuir para a aproximação entre os bancos e os microempreendedores da base da pirâmide, promovendo a inclusão bancária e trazendo, com isso, todos os benefícios que ela é capaz de oferecer a esses sujeitos, à economia e ao País como um todo. Evidenciar essas questões foi, acredita-se, a maior contribuição deste trabalho.

\section{Recomendações para pesquisas futuras}

Os resultados dessa pesquisa abrem espaço para a realização de outros estudos capazes de contribuir para a construção do conhecimento acerca do comportamento do microempreendedor de subsistência que mantém suas atividades em aglomerados e favelas. Exemplos desses estudos seriam aqueles que se dedicassem a estratificar a população que compõe a base da pirâmide social, considerando que o empreendedor de subsistência apresenta comportamentos e percepções diferentes de outras parcelas dessa população, identificando as fontes da exclusão bancária nos diversos nichos que a compõem.

Tornam-se também relevantes pesquisas que busquem compreender os impactos das políticas públicas, como também interferências de entidades privadas, na lógica do aprendizado no que se refere à educação financeira, considerando que tais políticas deveriam priorizar e promover a utilização e o consumo conscientes de bens e serviços disponíveis em instituições financeiras, com o propósito efetivo de promover a inclusão bancária.

Estudos que permitam conhecer a percepção de funcionários dos bancos a respeito desse público são outra via de pesquisa interessante, na medida em que podem permitir ricas comparações entre a visão do microempreendedor da base da pirâmide e a instituição financeira que o atende. 
Estas e outras investigações que contemplem o tema inclusão bancária são bem-vindas e oportunas, dada a importância e mesmo a urgência desse tópico para o desenvolvimento dessas pessoas e do País, de forma geral. Acredita-se que, diante de todo o potencial que apresenta no combate aos desafios aqui encontrados, a essa responsabilidade o marketing não pode se furtar. 


\section{REFERÊNCIAS}

ALBAGLI, S.; MACIEL, M. L. Capital social e empreendedorismo local. Rio de Janeiro: UFRJ, 2002.

ANDERLONI, L. et al. Access to bank accounts and payment services, in: ANDERLONI, L. et al. (ed) New Frontiers in Banking Services: emerging needs and tailored products for untapped markets, Nova York, Springer, 2006.

ANDERSON, J.; MARKIDES, C. Strategic innovation and the base of the pyramid. MIT Sloan Management Review, v. 49, n. 1, p. 83-88, 2007.

BADER, M.; SAVOIA, J. R. F. Logística da distribuição bancária: tendências, oportunidades e fatores para inclusão financeira. RAE - Revista de Administração de Empresas, Fundação Getúlio Vargas, São Paulo, v. 53, n. 2, p. 208-215, mar./abr., 2013a.

BADER, M.; SAVOIA, J. R. F. Inclusão financeira: como a tecnologia e a modernização das transações bancárias impulsionam a economia e transformam a relação do mundo com o dinheiro. São Paulo: Saint Paul Editora, 2013b.

BANCO CENTRAL DO BRASIL. Relatório de inclusão financeira. n. 2. 2011.

BARDIN, L. Análise de Conteúdo. Lisboa: Edições 70, 2011.

BARROS, C. Consumo, hierarquia e mediação: um estudo antropológico no universo das empregadas domésticas. Anais do $30^{\circ}$ EnANPAD, 2006.

BECK, T.; TORRE, A. L. The Basic Analytics of Access to Financial Services. World Bank Policy Research Working Paper 4026, October 2006.

BERTRAND, M.; MULLAINATHAN, S.; SHAFIR, E. Behavior economics and marketing in aid of decision making among the poor. Journal of Public Policy \& Marketing, v. 25, n. 1, p. 8-23, Spring 2006.

BRASIL. Saiba como funciona e como participar do Programa Minha Casa, Minha Vida. 2014. Disponível em: <http://www2.planalto.gov.br/excluir-historico-nao-sera-migrado/saibacomo-funciona-e-como-participar-do-programa-minha-casa-minha-vida $>$.Acesso: 2jun. 2014.

CASTILHOS, R. B. Subindo o morro: consumo, posição social e distinção entre famílias de classes populares. 2007. 204 f. Dissertação (Mestrado em Administração) - Escola de Administração, Universidade Federal do Rio Grande do Sul, Porto Alegre, 2007.

CÓRDOVA, R.; DINIZ, E. H.; GONZALEZ, L. Inclusão financeira e correspondentes bancários. GV EXECUTIVO, São Paulo, v. 3, n. 1, p. 58-59, jan./jun. 2014.

COSTA, F. N. Microcrédito no Brasil. Texto para Discussão. Instituto de Economia da UNICAMP n. 175, abr. 2010.

CROCCO, M. A.; SANTOS, F.; FIGUEIREDO, A. Exclusão financeira no Brasil: uma análise regional exploratória. Revista de Economia Política, São Paulo, v. 33, n. 3, p. 505526, jul./set. 2013.

CUNHA, H. M. S., DOS SANTOS, J. C. R., \& CERQUEIRA, L. S. Comportamento do consumidor de baixa renda em Lauro de Freitas: um estudo dos fatores que influenciam na aquisição de televisores. Revista Formadores, v. 6, n. 1, p. 67, 2013. 
DOLABELA, F.; FILION, L. J. Fazendo revolução no Brasil: a introdução da pedagogia empreendedora nos estágios iniciais da educação. Revista de Empreendedorismo e Gestão de Pequenas Empresas, São Paulo, v. 3, n. 2, 2013.

FILION, L. J. From entrepreneurship to entreprenology. 1997. Disponível em: <http:/ /www.usasbe.org/knowledge/proceeding/1997/p207filion.pdf>.Acesso em: 11 jul. 2014.

FREITAS, A. F. Organizações de microfinanças: inovações e desafios para a inclusão financeira. Revista de Administração da UFSM, Santa Maria, Entrevistado 9 - mar., v. 6, n. 1, p. 39-54, jan./mar. 2013.

GLOUKOVIEZOFF G. L'exclusion bancaire et financière des particuliers. In: L'Observatoire National de la Pauvreté et de L'exclusion Sociale, Les travaux de l'Observatoire, Paris: La Documentation Française, 2004. p. 167-205.

GLOUKOVIEZOFF G., From Financial Exclusion to Overindebtedness: The Paradox of Difficulties for People on Low Income? In: ANDERLONI, L.; BRAGA, M. D.; CARLUCCIO, E. (Eds.). New frontiers in banking services. Emerging needs and tailored products for untapped markets, Berlin: Springer Verlag, 2006. p. 213-245.

HONOHAN, P. Measuring Microfinance Access: Building on Existing Cross-Coutry Data. World Bank Policy Research Working Paper 3606, May 2005.

JULIEN, P. A. Empreendedorismo regional e economia do conhecimento. São Paulo: Saraiva, 2010 .

MATTOSO, C. L. A posição social, sua influência no consumo da base da pirâmide e a adoção de um novo modelo de estratificação social, PMKT - Revista Brasileira de Pesquisas de Marketing, Opinião e Mídia, São Paulo, v. 12, p. 46-58, abr. 2013.

MINISTÉRIO DO DESENVOLVIMENTO SOCIAL. Inclusão Bancária. 27 out. 2009. Disponível em: <http://www.mds.gov.br/saladeimprensa/noticias/2009/outubro/mds-e-caixapromovem-inclusao-bancaria-dos-beneficiarios-do-bolsa-familia>. Acesso em: 25 maio 2014.

OHANYAN, A. Bringing banking to the poor or the poor back to banking? International Studies Review, v. 5, n. 3, p. 412-415, Sep. 2003.

OLIVEIRA, J. B.; PEGHINI, P.; MENDONÇA, J. M. B.; MENCK, A. C. M. Entrepreneurial Attitudes: Comparing Independent Business Owners With Franchisees. International Journal of Business and Social Research (IJBSR), v. 4, n. 3, p. 126-136, Mar. 2014.

PARENTE, Juracy; BARKI, Edgard. Oportunidades na baixa renda. GVexecutivo, v. 4, n. 1, p. 33-37, 2005.

PRAHALAD, C. K. A riqueza na base da pirâmide: como erradicar a pobreza com o lucro. Porto Alegre: Bookman, 2008.

RIBEIRO, A. H. P.; FURRIER, M. T.; ACEVEDO, C. R. Reflexões sobre as políticas públicas relacionadas ao programa de inclusão para a população de baixa renda no Brasil. Revista Brasileira de Marketing, São Paulo, v. 9, n. 1, p.111-123, jan./abr. 2010.

ROCHA, A.; SILVA, J. F. Inclusão social e marketing na base da pirâmide: uma agenda de pesquisa. Revista de Administração de Empresa - eletrônica, v. 7, n. 2, Art. 23, jul./dez. 2008.

SACHS, J. D. The end of poverty: economic possibilities for our time. New York: Penguin, 2005.

SARTI, C. A. (2003a [1996]). A família como espelho: um estudo sobre a moral dos pobres (2a ed. rev.) São Paulo: Cortez. 
SOARES, M. M.; MELO SOBRINHO, A. D. Microfinanças: o papel do Banco Central do Brasil e a importância do cooperativismo de crédito. Brasília: BCB, 2008.

YUNUS, M. Criando um negócio social: como iniciativas economicamente viáveis podem solucionar os grandes problemas da sociedade. Rio de Janeiro: Elsevier, 2010.

VALE, G. M. V. Empreendedorismo, marginalidade e estratificação social. Revista de Administração de Empresa, São Paulo, v. 54, n. 3, p. 310-321, mai./jun. 2014.

\footnotetext{
${ }^{i}$ Bancarização: Para a FEBRABAN (2011) o que define bancarização é o nível de acesso aliado ao grau de uso dos serviços financeiros. A Revista GV EXECUTIVO, v. 13, n. 1, jan./jun. 2014, trata o termo "acesso" como disponibilidade de serviços de qualidade a um custo razoável; já o "uso" é definido como o seu consumo.

ii $\mathrm{O}$ entrevistado se refere à Avenida do Contorno, importante via da cidade de Belo Horizonte que, no entanto, localiza-se a razoáveis quarteirões de distância da região onde a pesquisa foi realizada.

iii Tanto rua do Ouro, rua Capivari e avenida Men de Sá são vias importantes nos bairros que circundam o Aglomerado da Serra. Contudo, também não se localizam propriamente perto dos microempreendimentos pesquisados, considerando-se a extensão da região que envolve as sete vilas do Aglomerado.
} 